\section{Standardised training is the key to accuracy in triage}

To the Editor: We read with interest Goldstein et al. $\mathrm{s}^{[1]}$ article, 'The accuracy of nurse performance of the triage process in a tertiary hospital emergency department in Gauteng Province, South Africa (SA)'. It is encouraging to observe research-driven improvement in the use of the SA Triage Scale (SATS). The downstream effect of accurate triage on patient safety is known, and more effort is needed to improve the use of the SATS. ${ }^{[2]}$ We are aware that training in its use tends to be haphazard (in the public and private sector), with little standardisation of what is taught in different settings by different triage trainers. The Emergency Medicine Society of South Africa provides resources for training (manuals, posters and videos), but fails to provide a structured curriculum or assessment strategy that trainers can adopt. ${ }^{[3]}$ Goldstein et al. ${ }^{[1]}$ mention in-service training, but unfortunately do not provide detail with regard to the training.

There are several reasons why accurate triage is important. It has a direct effect on patient safety; it also improves efficiency by appropriately directing patients to receive care in order of priority. ${ }^{[2]}$ In doing so, triage improves quality of care and decreases the hidden cost associated with under-, over- and no triage. Taking a step away from patient-centred motives, business-related motives, such as the use of the SATS for billing purposes, would also be affected by accuracy. It may appear to be a good idea from the outset, but as triage accuracy is likely to be either similar or (more likely) worse than that reported by Goldstein et al. ${ }^{[1]}$ this ill-conceived practice (currently used by many private emergency centres) means that an overtriaged patient is also an overcharged customer, leading to the overtriaged subsidising the undertriaged. This issue becomes murkier when one considers that the SATS purposely overtriages - a safety net, built into every major triage tool. Furthermore, the SATS triages patients to a possible admission, not a resource requirement. If a patient already pays for an admission, why must they then pay even more in the emergency centre?

The key to using any instrument well, is training, practice and audit, and in the case of the SATS, it comprises continuous training and assessment. Helpful adjuncts include technology, such as the SATS application by The Open Medicine Project of South Africa. ${ }^{[4]}$ However, at the core, the solution remains training. We supply a structured SATS provider curriculum (including a refresher course), with a standardised assessment, alongside instructor training, for public emergency centres in the Western Cape. We recommend the creation of a triage committee at each facility to include staff from the emergency centre and the training department. At Paarl Hospital, the Western Cape's first facility to achieve a full cohort of SATS-trained providers using this curriculum, triage accuracy is in keeping with the national core standards set out by the Department of Health. ${ }^{[5]}$ As the training programme is rolled out, more emergency centres locally are nearing this goal. An open-access SATS provider curriculum is available from our provincial website: http://www.emct.info/triage.html

\section{S R Bruijns}

Emergency Medicine, University of Cape Town, South Africa stevan.bruijns@uct.ac.za

\section{P Louw}

Emergency Centre, Paarl Hospital, South Africa

\section{A Kuiler}

Emergency Centre, Khayelitsha Hospital, South Africa

\section{E Esterhuyse}

Emergency Centre, Worcester Hospital, South Africa

\section{Y N Magerman}

Western Cape College of Nursing, Cape Town, South Africa

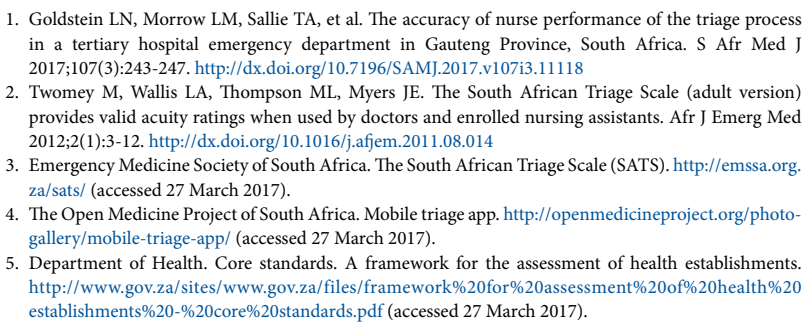
in a tertiary hospital emergency department in Gauteng Province, South Africa. S Afr Med J in a tertiary hospital emergency department in Gauteng Province, S
2017;107(3):243-247. http://dx.doi.org/10.7196/SAMJ.2017.v107i3.11118

2. Twomey M, Wallis LA, Thompson ML, Myers JE. The South African Triage Scale (adult version provides valid acuity ratings when used by doctors and enrolled nursing assistants. Afr J Emerg Med 2012;2(1):3-12. http://dx.doi.org/10.1016/j.afjem.2011.08.014

3. Emergency Medicine Society of South Africa. The South African Triage Scale (SATS). http://emssa.org. za/sats/ (accessed 27 March 2017)

4. The Open Medicine Project of South Africa. Mobile triage app. http://openmedicineproject.org/photogallery/mobile-triage-app/ (accessed 27 March 2017)

5. Department of Health. Core standards. A framework for the assessment of health establishments. http://www.gov.za/sites/www gov za/files/framework 020 for $\% 20$ assessment $\% 200$ fo 20 health\%20 establishments\%20-\%20core\%20standards.pdf (accessed 27 March 2017).

S Afr Med J 2017;107(7):546. DOI:10.7196/SAMJ.2017.v107i7.12508 